systematic literature search has found no such evidence or guidance on the withdrawal of gastrostomy feeding in patients with MND. We present the challenges faced when a patient with MND was transferred to hospice IPU requesting withdrawal of PEG feeding and the need for further research; as hospices may increasingly play a role in withdrawal of treatment in MND in future.

\section{DIETETIC INTERVENTION FOR PATIENTS WITH ADVANCED CHRONIC KIDNEY DISEASE - A CONSERVATIVE MANAGEMENT APPROACH}

Dawn Yokum, Jaryn Go, Ruby Tayab, William White, Magdi Yaqoob. Department of Renal Medicine and Transplantation, Circulatory and Metabolic Sciences Clinical Academic Unit, Royal London Hospital, Barts Health NHS Trust, UK

\subsection{6/spcare-2019-mariecuriepalliativecare.46}

Conservative management (supportive care) is defined as individuals with advanced chronic kidney disease (CKD) who choose not to undergo dialysis (supported by their kidney team).

A renal supportive care (SC) outpatient service has existed for over 10 years at this large renal unit.

Dietetic management in this population is complex, with the aim being to alleviate and/or reduce the risk of symptoms associated with advanced CKD and support quality of life. This may involve dietetic interventions such as: management of blood biochemistry (potassium, phosphate and mineral bone disease), fluid status (no added salt), low protein and nutritional support.

The aim is to evaluate current dietetic practice using a snapshot of the SC population

The method used was a random sample of selected patients. Data collected included demographics, prevalence of abnormal blood results, low protein diet advice and nutritional support.

The results for twenty patients (11\% of the SC population) were used. Median age 80.5, range: 70 - 99years). Median duration under SC service: 23.5 (range: <1-56) months

Eighteen patients (90\%) had received dietetic input. Half of these patients $(n=9)$ required a low protein diet and $33 \%$ $(n=6)$ were given nutritional supplementation. Three patients $(15 \%)$ had either a recent elevated blood potassium or phosphate level.

In conclusion, the complexity of dietetic management in this SC patient population highlights the importance of a renal dietitian's involvement to help alleviate symptoms of advanced CKD and support quality of life. Further research into outcomes including patient/carer experience surveys is warranted.

\section{DEVELOPING A GUIDELINE TO IMPROVE AND STANDARDISE PRACTICE IN WITHDRAWING NON- INVASIVE VENTILATION IN THE END OF LIFE SETTING}

Lucy Williams, Caitlin Morgan, Rachel McCoubrie. Bristol Royal Infirmary, UK

10.1136/spcare-2019-mariecuriepalliativecare.47

Many patients who are reliant on NIV have chronic and incurable diseases. These include progressive neuromuscular diseases and irreversible airways disease. Hand in hand with these diagnoses goes significant frailty. It is important when caring for these patients that we listen to their wishes at every stage. It's especially important when they may be coming towards the end of their lives. Often at this stage people have become dependent on their ventilators and withdrawing this support must be a sensitive and pre planned procedure. There are complex ethical and emotional dynamics at play for both patients and medical professionals. This only heightens the need for meticulous planning and frank discussion.

Our survey of junior doctors in the hospital setting revealed although $85 \%$ of people had been involved with managing NIV in end of life situations, $58 \%$ did not feel confident in doing so. This has a significant effect on both the patient and the junior doctor. Patients are having unacceptable deaths due to junior doctor lack of knowledge and disempowerment.

Following review of these results we undertook the development of a guideline to allow better care during this these end of life situations. This was written with multidisciplinary team input and was subsequently reviewed by a junior doctor panel.

Once globally approved it will be introduced trust-wide and junior doctors will be re-surveyed to measure impact on practice.

\section{THE NATURE OF COMPLEX NEED IN SPECIALIST PALLIATIVE CARE REFERRALS}

${ }^{1}$ Connie Swenson, ${ }^{2}$ John MacArtney, ${ }^{3}$ Rachel Perry, ${ }^{4}$ Lucy Hetherington, ${ }^{5}$ Lisa GrahamWisener, ${ }^{6}$ Hazel Lamberton, ${ }^{4}$ Emma Carduff, ${ }^{7}$ Scott Murray, ${ }^{8}$ Anne Finucane. ${ }^{7}$ NHS Lothian, UK; ${ }^{2}$ Warwick Medical School, UK; ${ }^{3}$ Marie Curie West Midlands, UK; ${ }^{4}$ Marie Curie Glasgow, UK; ${ }^{5}$ School of Psychology, Queen's University Belfast, UK; ${ }^{6}$ Marie Curie Belfast, UK; ${ }^{7}$ Primary palliative care research group, University of Edinburgh, UK; ${ }^{8}$ Marie Curie Hospice Edinburgh, UK

\subsection{6/spcare-2019-mariecuriepalliativecare.48}

Background Understanding complex need as the defining characteristic of episodes requiring specialist palliative care (SPC) is key to hospice service development. A single definition of complex need is lacking, however markers of complex need include: presence of multiple needs, needs across different domains, interactions between different needs and fluctuating needs. We examined which markers of complex need are present in referrals to a hospice service.

Methods Mixed-method service evaluation consisting of a casenote review and staff focus groups.

Results Physical needs were most frequently described in referral documents (91\%) though needs were present across all domains. Markers of complexity across more than one domain were present in $95 \%$ of referrals. Psychological, social or spiritual needs were described in $68 \%$ of referrals; fluctuating needs in $67 \%$; carer needs were documented in $52 \%$. Referral forms were viewed as limited for capturing complexity. The quality of a referral was perceived as influenced by the experience and confidence of the referrer, their knowledge of the services available, the resources available to the referrer to meet the patients needs and the patient's diagnosis.

Conclusions Complex needs were documented in most referrals to hospice services. However, clarity on what service was being sought to meet a person's needs was lacking. There is scope for hospices to improve referral quality by defining 
what services are offered to meet which needs; communicating regularly with referrers, and providing education or training to support referrers to improve their ability to meet patient needs directly.

\section{REVIEW OF POTENTIAL GEOGRAPHICAL DISPARITIES IN ACCESS TO ANTI-FIBROTIC MEDICATION AND CLINIC- BASED SPECIALIST PALLIATIVE CARE FOR PATIENTS WITH IDIOPATHIC PULMONARY FIBROSIS}

${ }^{1}$ Kym Wakefield, ${ }^{2}$ Evelyn Palmer, ${ }^{2}$ Claire Donaldson, ${ }^{1}$ Anne-Marie Bourke, ${ }^{2}$ lan Forrest. ${ }^{1}$ Marie Curie, UK; ${ }^{2}$ Newcastle upon Tyne Hospitals NHS Foundation Trust

10.1136/spcare-2019-mariecuriepalliativecare.49

Background Idiopathic pulmonary fibrosis (IPF) is a progressive interstitial lung disease of unknown origin (NICE, 2013). Disease-modifying anti-fibrotics are restricted to patients who meet specific criteria and are prescribed by regional IPF centres (NICE, 2016; NICE, 2018). Patients should be offered best supportive care from diagnosis (NICE, 2013). In January 2016 specialist palliative care (SPC) support was embedded in a regional IPF clinic. Initial service review (Kavanagh, 2017) suggested potential geographical disparities in access to both anti fibrotics and clinic-based SPC.

Aim To repeat the 2016 review to assess whether geographical disparities have changed over time.

Methods The sex, age and postcode of all patients with known IPF prescribed anti-fibrotics or seen by clinic-based SPC between January 2016 and April 2019 were collected retrospectively and geographically plotted. Chi squared goodness of fit was used to calculate statistical significance.

Results 398 patients were started on anti-fibrotics (male:female 330:68, mean age 74.7). Geographical plotting shows significant variation by region $(\mathrm{P}<0.01)$ ranging from 6.1 to 16.2 per 100,000 population, with comparatively low numbers of patients from Cumbria and North Durham (See figure 1). 80 patients were seen by SPC (male:female 65:15, mean age 74.9). Again, geographical plotting shows significant variation by region $(\mathrm{P}<0.02)$ ranging from 0.9 to 4.5 per 100,000 population, with a higher proportion of patients from NewcastleGateshead (See figure 2).

Discussion Geographical distribution of patients seen by clinicbased SPC appears to have changed little since 2016, with

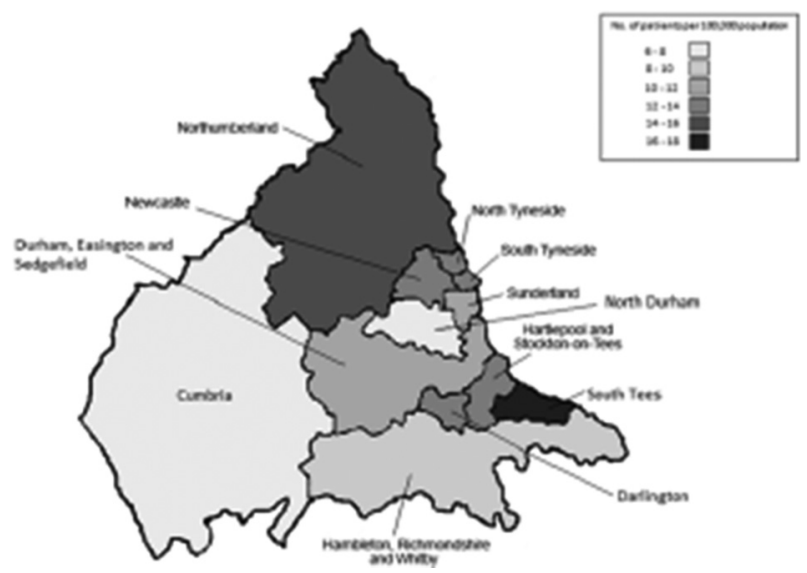

Abstract 49 Figure 1 Geographical distribution of patients started on antifibrotics Jan 2016 - Apr 2019

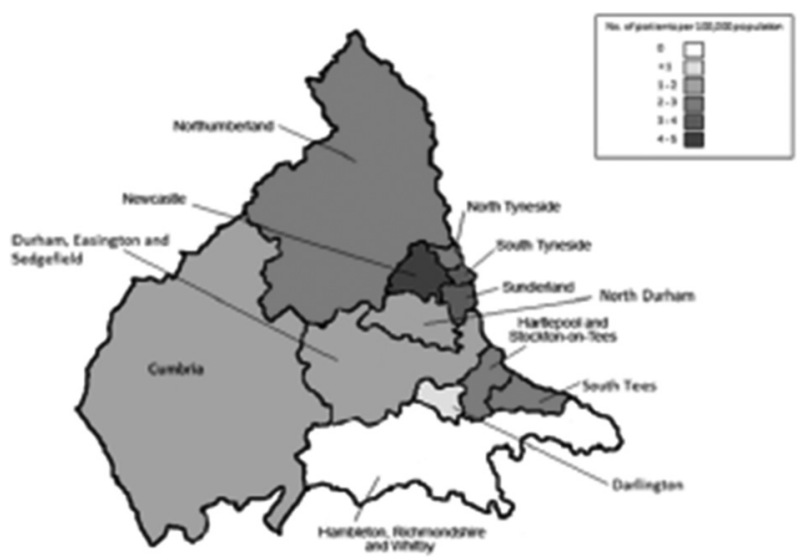

Abstract 49 Figure 2 Geographical distribution of patients reviewed by SPC in ILD clinic Jan 2016 - Apr 2019

clear centralisation to Newcastle-Gateshead. Speculatively, reasons for this could include travel distances and local palliative care provision. Geographical disparity in antifibrotic prescription is more difficult to account for and requires further investigation.

\section{REFERENCES}

1. National Institute for Health Care and Excellence (NICE). (2013) Idiopathic Pulmonary Fibrosis in Adults (CG163) [online]. https://www.nice.org.uk/guidance/cg163. Accessed 04/07/2019.

2. National Institute for Health Care and Excellence (NICE). (2016) Nintedanib for Treating Idiopathic Pulmonary Fibrosis (Technology Appraisal Guidance TA379) [online]. https://www.nice.org.uk/guidance/ta379. Accessed 04/07/2019.

3. National Institute for Health Care and Excellence (NICE). (2018) Pirfenidone for Treating Idiopathic Pulmonary Fibrosis (Technology Appraisal Guidance TA504) [online]. https://www.nice.org.uk/guidance/ta504/chapter/1-Recommendations. Accessed 04/07/2019.

4. Kavanagh $E$, et al. Integration of specialist palliative care into a tertiary nonmalignant service: evaluation of potential geographical disparity. BMJ Supportive \& Palliative Care 2017;7(Suppl 1):A33-A34.

\section{Systematic Reviews}

\section{FAMILY-CENTRED CARE IN HOSPICES: WHAT ABOUT THE CHILDREN?}

Steve Marshall, Richard Harding, Katherine Bristowe, Rachel Fearnley. King's College London, UK

\subsection{6/spcare-2019-mariecuriepalliativecare.50}

Palliative care professes to take a family-centred approach to patient care. ${ }^{1}$ However, children under 18 may not feel included when a parent is being cared for in a hospice. ${ }^{2}$ A systematic literature review of PsychINFO, Medline, Embase, Scopus and Web of Science was conducted, with no restriction on publication date. Nineteen studies met the inclusion criteria, all reporting primary data from children under 18 , whose parent has a life-limiting illness.

Findings from the review reveal that:

- Children and young people often feel excluded when a parent is dying.

- Communication about prognosis does not routinely happen with children.

- For children, the terminal period is generally more stressful than after the death. 